\title{
DE MESTRE-ESCOLA A PROFESSORA PÚBLICA: A HISTÓRIA DE VIDA DE MARIA PUREZA CARDOSO ARAÚJO (1920 A 2013) ${ }^{1}$
}

\author{
Jane Bezerra de Sousa ${ }^{2}$
}

UFPI

\section{RESUMO}

Este trabalho tem como objetivo analisar a história da profissão docente no Piauí, por meio do registro de vida da professora Maria Pureza Cardoso Araújo. O recorte cronológico adotado no presente artigo tem início no ano de 1937, data de seu ingresso no magistério, e 1985, ano de sua aposentadoria. No início de sua atividade docente, era mestre de varanda ou mestre ambulante, em escolas familiares, no final dos anos 1940. Foi contratada posteriormente como professora pública na cidade de José de Freitas (PI), na localidade Palmeirinha. Parte de sua vida profissional foi dedicada à Escola Municipal Estevam Joaquim de Sousa. Como fontes da pesquisa, analisou-se um vídeo construído por ocasião da celebração de seus 90 anos idade, o qual mesclava aspectos do "eu pessoal" com o "eu profissional", e realizou-se entrevista com a professora. Os dados foram examinados de acordo com as ideias de autores como Goodson (1995), e de pensadores da historiografia local, como Ferro (1996), Reis (2009) e Silva (2012). O estudo ora realizado remete aos seguintes aspectos: os contratos de mestre-escola foram superados e estes passaram a ser professores públicos; os mestres de varanda coexistiram com o novo modelo de professor público modernizador da nação; a história das instituições escolares e da cultura escolar. Palavras-chave: História de vida; Profissão docente; Memória.

\section{THE SCHOOLMASTER TO PUBLIC SCHOOL TEACHERS: THE LIFE STORY OF MARIA PUREZA CARDOSO ARAÚJO (1920 - 2013)}

\begin{abstract}
This work aims to analyze the history of the teaching profession in Piauí through the life story of Professor Maria Pureza Cardoso Araújo. The chronological cut adopted in the article has its beginning in 1937, due to the entry of the teacher in teaching and in 1985, the year of his retirement. Early in his teaching activity was balcony master or master walking in familiar schools in late 1940. It was subsequently hired as a public teacher in the city José de Freitas (PI), in Palmeirinha location. Part of his professional life was dedicated to Municipal School Estevam Joaquim de Sousa. As research sources analyzed a video built during the celebration of the 90 years age that blended aspects of "personal" with "professional self" and conducted an interview with the teacher. We analyzed the data according to the authors of such ideas as: Goodson (1995); authors of local history as Ferro (1996), Reis (2009) and Silva (2012). The life story of Pureza teacher refers the following analyzes: the schoolmaster contracts were overcome and these have become public school teachers; the balcony Masters coexisted with the new modernizing public teacher model of the nation; history of educational institutions and school culture.
\end{abstract}

Keywords: Life story; Teaching profession; Memory. 


\section{INTRODUÇÃO}

Nas aulas de história da educação do Brasil, um dos conteúdos abordados é a atuação dos mestres ambulantes, ou mestres de varanda ou, ainda, mestres-escola, como são chamados os professores que ministravam suas aulas, geralmente, em escolas familiares, sem prédios públicos, com horários e conteúdos determinados por eles mesmos.

Tal fato ocorreu na educação brasileira principalmente durante o Império, em razão da escassez de pessoas letradas e de professores que atendessem a todas as regiões do país. A maioria dos jovens da elite, que continuavam seus estudos naquela altura, tinham sua instrução elementar efetivada por intermédio desses mestres pagos, como se verifica em Veiga (2007):

Quanto aos filhos das elites fundadoras e frequentadoras desses ambientes, não era usual a frequência dos três níveis de ensino em escolas. A maioria dos jovens que frequentaram aulas avulsas ou escolas secundárias e depois um curso superior, por exemplo, não aprendeu as primeiras letras em estabelecimentos públicos, mas em casa - pela mão dos pais, de algum parente ou com um mestre pago. Só a partir de meados da década de 1850 , com o crescimento do número de colégios particulares, os filhos das elites também puderam iniciar sua instrução elementar em instituições deste tipo. (VEIGA, 2007, p. 186).

Villela (2007) remonta sua análise sobre esse tema ao período da vinda da Família Real para o Brasil, que resultou em medidas educacionais na instrução elementar.

[...] esse nível de ensino, por muito tempo ainda, quase totalmente restrito à esfera privada, ou seja, por conta das famílias que, dependendo da importância e do sentido que conferiam à aquisição da cultura letrada, realizavam esforços, ou não, para enviar e manter seus membros numa "escola". Mas, que escola? (VILLELA, 2007, p. 98).

Como trabalho de pesquisa de campo, os alunos foram orientados a investigarem sobre as práticas desses mestres no Piauí que, embora tenham sido marcantes no período imperial, tiveram sua presença notada até meados do século XX. Para Villela (2007), as escolas normais no século XIX substituiriam definitivamente o mestre-escola. No Piauí, a escola normal foi criada em 1864, posteriormente, fechada e, após três tentativas, reaberta oficialmente em 1910. Tal fato mostra a coexistência, no Estado, de professoras normalistas e mestres-escolas.

Em um dos trabalhos apresentados pelos alunos em sala, foi possível conhecer a história de vida de Maria Pureza Cardoso Araújo, por meio de um vídeo construído na ocasião da celebração de seus 90 anos idade, que mesclava aspectos de seu "eu pessoal" com o "eu profissional".

Chamou atenção o fato de a professora Pureza iniciar na profissão docente como mestre-escola e ser nomeada, futuramente, como professora pública. Dessa forma, percebeu-se o quanto ouvir e pesquisar a sua história de vida seria uma experiência significante para a história da educação no Piauí, no sentido de reafirmar a presença do mestre-escola na educação piauiense, coexistindo com o novo modelo de professor público modernizador da nação, estabelecido no final dos anos 1930 e 1940.

Após assistir ao vídeo com várias entrevistas, editado por seu neto, Marcondys Sousa, ouviram-se diversos depoimentos, tanto de ex-alunos como dela mesma, onde retratavam o cotidiano do espaço escolar no qual atuou como professora. Ademais, foi produzida uma entrevista com Dona Pureza (como é conhecida), então com 93 anos de 
idade, em uma tarde prazerosa de muitas histórias sobre sua formação, sua vida pessoal, seus alunos e suas práticas escolares.

Assim, após a análise das fontes, este artigo foi escrito, com o objetivo de investigar e socializar a história de vida dessa professora, mãe e mulher desbravadora do conhecimento e orgulhosa de sua profissão.

\section{INFÂNCIA E FORMAÇÃO NO GRUPO ESCOLAR PADRE SAMPAIO}

Investigar a história de vida da professora Maria Pureza Cardoso Araújo é dar voz ao professor e ao seu desenvolvimento profissional. Como afirma Goodson (1995), permitir ouvir a voz dos professores é conhecer suas experiências de vida e o seu ambiente sociocultural, que são ingredientes da pessoa que somos, do nosso sentido, do eu.

O estilo de vida, dentro e fora da escola, sua identidade e cultura, têm impacto sobre a prática educativa. Portanto, à medida que se revisitou a história de vida da professora Pureza, empreenderam-se estudos referentes à vida de professores, os quais puderam ampliar os conhecimentos acerca da história da educação, analisando as experiências dos mestres-escola, no Piauí, que se tornaram professores públicos, assim como as instituições escolares que desempenharam o magistério e a cultura escolar durante o espaço temporal considerado no estudo.

Segundo Goodson (1995, p. 75),

os estudos referentes às vidas dos professores podem ajudar-nos a ver o indivíduo em relação com a história do seu tempo, permitindo-nos encarar a intersecção da história de vida com a história da sociedade, esclarecendo, assim, as escolhas, contingências e opções que se deparam ao indivíduo. 'Histórias de vida' das escolas, das disciplinas e da profissão docente proporcionariam um contexto fundamental. A incidência inicial sobre a vida de professores reconceptualizaria, por assim dizer, os nossos estudos sobre escolaridade e currículo.

Maria Pureza Cardoso Araújo nasceu em 26 de junho de 1920, no povoado Meios, localizado no município de União. Filha de José Cardoso de Araújo, conhecido como José Atanazio (era marceneiro e consertava máquinas), e de Francisca Maria da Conceição (do lar). Dessa união, nasceram os filhos Pureza, Alcides, Raimundo, João Damascena, Mariinha, Davino, Mestre Eulálio, Manoel Alcides e Antonio. A mãe de Dona Pureza morreu de uma doença conhecida popularmente como fogo selvagem. A professora relembrou o fato emocionada, mencionando que, em muitas situações, abanava a mãe o dia inteiro, devido ao calor intenso que a doença provocava pelo corpo.

Em 1920, quando Dona Pureza nasceu, na Primeira República, tal fato coincidiu com um marco educacional piauiense: a construção do prédio da Escola Normal do Piauí. Conforme Ferro (1996, p. 98), "O prédio em questão teve o seu projeto realizado em 1919 e iniciada a construção em 1920. Em 1924, as solenidades de transmissão do governo estadual já foram realizadas em suas dependências".

Em 1910, a escola normal foi reaberta oficialmente, após três tentativas de funcionamento no século anterior. Na década de 1920, de acordo com Sousa (2009), o analfabetismo e o descaso com a instrução eram preocupantes no Brasil. No Piauí, não era diferente: o baixo índice de escolaridade na Primeira República afligia os governantes. No 
recenseamento de 1920, realizado pelo IBGE, o Estado possuía $86 \%$ de sua população composta por analfabetos.

Por outro lado, o referido período foi marcado pela modernização das cidades brasileiras. Um dos paradigmas apropriados pelas classes tradicionais foi a disseminação dos grupos escolares por todo o Brasil, os quais, de certa forma, representavam um símbolo de modernização e de demonstração de prestígio e poder, ao lado da luz elétrica, da água encanada, das praças, das ruas alargadas para automóveis, da força policial.

Após a morte de sua mãe, Pureza foi morar, aos sete anos de idade, no município de José de Freitas, com o irmão conhecido como Mestre Alcides. Nessa oportunidade, estudou no Grupo Escolar Padre Sampaio, tendo como primeira professora Agripina de Castro Portela.

O retrocitado grupo escolar foi fundado em 19 de abril de 1928, resultado da junção da antiga escola reunida Padre Sampaio Castelo Branco (1925) e pela fusão das escolas isoladas estadual e municipal, e fazia parte do projeto de interiorização desse modelo de escola, iniciado em 1922, com a fundação do Grupo Escolar Miranda Ozório, na cidade de Parnaíba (PI). Esse padrão de escola foi idealizado pelos republicanos e tinha funcionamento regular, com prédio próprio, diretor, secretário, horário escolar, séries, livros e fardamentos, além da presença da professora normalista.

Na Vila do Livramento (atual município de José de Freitas - PI), as atividades escolares marcaram o início do século XX. A escola foi situada na Rua Hugo Napoleão. Documentos registrados no Arquivo Público de Teresina (Anexo G) mencionam que o grupo era instalado num salão, dividido por gradil de madeira, para funcionamento nos turnos: manhã $1^{\circ}$ e $2^{\circ}$ anos e a tarde $2^{\circ}$ e $4^{\circ}$ anos (SILVA, 2012, p. 89).

O grupo recebeu esse nome em homenagem a Joaquim Sampaio Castelo Branco, que nasceu no antigo Livramento, hoje município de José de Freitas (PI), em 1860. Faleceu no Rio, no ano de 1892. Presbítero da diocese do Maranhão, doutor em direito canônico, pela Academia Pontifícia de Santo Apolinário, Roma, bacharel em teologia, pela Universidade Católica de Paris. Foi professor de francês do Liceu Maranhense. Como jornalista, fundou, em São Luís, $O$ Mensageiro, que tanto se distinguiu na defesa da libertação dos escravos. Excelente orador sacro, publicou $O$ padre deve ser casado?, em que estuda exaustivamente o assunto, sob o ponto de vista histórico, apologético e teológico, bem como político, filosófico e social (TITO FILHO, 1988).

Ao falar do Grupo Escolar Padre Sampaio Castelo Branco, a professora relembrou aspectos marcantes da cultura escolar:

A professora Agripina entrava com a cartinha do $\mathrm{ABC}$ e os dois livros: Sei ler e Corações de Criança. A farda era uma saia azul com a blusa amarela de mangas compridas. As professoras tinham muita tolerância. Agripina foi minha professora de $1^{\mathrm{a}}$ a $4^{\mathrm{a}}$ série. Tinha a sabatina em que ganhávamos uns cartões chamados bônus, que depois eram utilizados nos leilões para arrematar coisas da escola. Pegava aulas particulares com Eduarda Santana e a chamava de madrinha Edu (Sousa,2010).

Era comum, nas práticas do grupo escolar, a professora lecionar na mesma turma, em todas as séries. O livro Corações de Crianças foi bastante utilizado nesse modelo de escola. A professora Amada Reis, ao estudar a história da educação, em Oeiras, faz uma análise dessa obra, bastante disseminada na época áurea dos grupos: 
Corações de Crianças é um livro de tamanho médio, medindo $12,5 \mathrm{~cm}$ por $18 \mathrm{~cm}$, de fácil transporte e manuseio, possui 169 páginas. Sua capa é dura, resistente e colorida, trazendo a estampa de um coração, contornada por uma fita arrematada por um laço, e no seu interior, uma paisagem com destaque de uma criança praticando uma boa ação. [...] Embora discreta, a capa do livro Corações de Crianças procura despertar, no público infantil a que se destina, o interesse e a curiosidade para que a criança, tal qual a figura sugere, trilhe os caminhos do saber e de uma vida reta e virtuosa (REIS, 2009, p. 234).

Ainda para esta autora, o livro trazia em seu bojo várias gravuras, reproduzindo cenas do cotidiano, as lições construídas pelos ideais republicanos de formar um cidadão movido pelo nacionalismo e moralismo, com normas e procedimentos cívicos, modelação do homem civilizado.

Lembro-me de um fato bastante interessante daquela época: a passagem de um avião, que procurava um local para pousar, era um teco-teco. Todas as crianças correram com as mãos para cima, admiradas, e o avião sem poder pousar. Próximo, tinha uma cerca com estacas, e o avião não conseguiu pousar, caiu e espetou a asa na cerca, mas os pilotos estavam vivos. Foi preciso desmontar o avião para levar os pedaços. As brincadeiras da época eram pular corda, começava lento até ficar mais rápido. Também tinha piqueniques (passeatas pelo interior, levando sacolas com comida). Lembro muito de Agripina. Era esposa do Dr. Antônio Portela e foi professora e diretora do grupo. As professoras do grupo que eu recordo eram: Luiza, Manoca, Hilda Vera e Laura. A prova era escalada os dias e geralmente eram de português, com ditados (SOUSA, 2010).

\section{TEMPOS DE JUVENTUDE E DE MESTRE-ESCOLA}

Aos 15 anos de idade, a professora Pureza foi morar com o pai em Altos. Ele já era casado com sua tia, Maria. Dois anos depois, foi morar com outro irmão, conhecido como João Damasceno, em Mocambinho, município de Campo Maior. Nesse período, mais ou menos em 1937, vivenciou sua primeira experiência como professora, dando aulas particulares aos filhos do senhor Conrado Saraiva, conhecido como Conrado Grosso.

A experiência de Dona Pureza em escolas familiares, no final dos anos 1940, quando o professor era pago pelo chefe de família, foi muito comum durante todo o século XIX. Para Costa Filho (2006), quando os filhos dos fazendeiros estavam em idade de ser alfabetizados, o pai contratava um professor, um mestre ambulante, que ministrava aulas na própria fazenda. Após a alfabetização, passavam a residir em outra cidade para continuarem os estudos. Este mesmo autor intitula essas escolas de familiares, que era uma prática comum para população residente na zona rural, envolvida no cotidiano das fazendas.

Essa mesma prática escolar foi largamente utilizada durante a Primeira República, no Piauí, como relata Ferro (1996, p. 123):

No período da Primeira República, a realidade piauiense reflete a realidade nacional e, no caso específico da educação, passou por várias reformas descontínuas. $\mathrm{O}$ ensino público e a iniciativa privada se 
mesclaram de forma interessante e, na República, o formal e o informal continuaram coexistindo e se completando de modo bastante peculiar.

A afirmação da professora Amparo Ferro é reafirmada no livro Velhas escolas e Grandes Mestres, de A. Sampaio, no qual biografa os mestres ambulantes de Esperantina e suas práticas, mostrando que era frequente sua atuação, ainda nos anos 1930 e 1940. Essas informações remetem à ideia de coexistência de grupos escolares, escolas isoladas e escolas familiares. Logo, pode-se afirmar que a presença do mestre-escola no modelo casa-escola continuou por um longo tempo, em um momento onde ocorria a construção de uma nação moderna que se consubstanciava no modelo grupo escolar/normalista. Nesse contexto, as escolas familiares continuaram existindo devido à rede pública de ensino não atender à demanda.

A aluna Teresinha, filha do senhor Corando Grosso, rememorou esse período: “meu pai a contratou para dar aulas para mim, meus irmãos e outras pessoas num salão dentro de casa. Lembro que ela era muito brincalhona e contava muitas histórias para nós" (SOUSA, 2010).

As aulas ministradas pela professora Pureza, nesses salões, eram de primeiras letras. Os alunos aprendiam a ler, escrever e contar. Como método, utilizavam-se a caligrafia, o ditado e o ensino das quatro operações.

Eu tinha dois alunos que moravam do outro lado do Rio Funilo. Eu passava os dias lá. Na volta, tomei banho no rio, era um domingo à tarde. $\mathrm{Na}$ segunda, amanheci com dores no corpo, febre paratifo. $\mathrm{O}$ rio estava contaminado e eu não sabia. Meu irmão foi buscar um farmacêutico em Nazaré para fazer uma poção. Eu fiquei muito fraca e fui morar novamente com o papai em Altos, e depois, novamente em Zé de Freitas, com meu irmão. Nessa época, passava roupas para ganhar dinheiro e comprar as minhas roupas. Foi quando informaram ao Senhor Zé Estevam que eu dava aulas particulares. Então, ele foi até a minha casa me convidar para ir a Palmeirinha ensinar particular aos seus filhos. Raimundo e Dos Anjos (os dois filhos de Zé Estevam), foram me buscar, a cavalo, a $36 \mathrm{~km}$ de José de Freitas. Eu montada de banda no cavalo de sela, passando pelos espinhos no boi dos Rodrigues e no capão da Luiza. Saímos de José de Freitas às 5 h da manhã e chegamos na Palmeirinha no dia 13 de outubro de 1947, às 19h. Todos estavam me esperando. No dia seguinte, fiz a matrícula de 50 alunos filhos dos proprietários da redondezas, a maioria do Carcará (SOUSA, 2010).

A professora iniciou seus trabalhos por volta de 1947, dando aula particular para crianças, filhas de José Saraiva de Sousa. A escola funcionava em uma sala construída ao lado da casa de José Saraiva de Sousa (José Estevam ${ }^{3}$ ). Ele mandou fazer a sala de aula, os bancos e a mesa da professora. Era uma sala de mais ou menos $32 \mathrm{~m}^{2}$ (4m de frente por $8 \mathrm{~m}$ de fundo). Os bancos eram de madeira, sem encosto e sem apoio para escrever. Segundo alguns ex-alunos, a turma, com o tempo, foi crescendo, com a inclusão de filhos de parentes e outros proprietários vizinhos, chegando a ter mais de 60 alunos.

\section{DE MESTRE-ESCOLA A PROFESSORA PÚBLICA}

Por volta de 1952/53, a escola foi legalizada pela prefeitura/Estado, com o nome de Escola Isolada Barão do Rio Branco ${ }^{4}$, e a professora particular foi contratada formalmente 
para dar aulas para os filhos dos fazendeiros da região. Tanto o salário da professora como o material escolar (livros/cartilha/ABC, tabuada, cadernos, lápis, material de registro) eram encaminhados pela Secretaria de Estado da Educação, por intermédio da prefeitura de José de Freitas.

A professora relatou que houve situações em que teve de se deslocar da comunidade em que morava, na zona rural de José de Freitas, para a capital, Teresina e, por meio de conhecidos na Secretaria Estadual de Educação, solicitou e conseguiu material escolar para a escola. Ela rememorou os nomes de dois secretários de educação com quem conseguiu ser recebida e obter material escolar: Joel Mendes e Baldoíno Barbosa de Deus. Tal fato ocorria devido à dificuldade em conseguir material escolar, pois não havia um fornecimento regular pela prefeitura.

Naquele momento, era difícil encontrar professores que se deslocassem para a zona rural, em virtude das dificuldades de acomodação e locomoção, além de terem de deixar a sua cidade de origem e sua família. Os mestres eram respeitados, principalmente porque, em sua maioria, eram contratados por proprietários de terra que possuíam dinheiro e prestígio social. O senhor Zé Estevam era subdelegado da região, responsável por garantir a ordem local, e gozava de bastante apreço por parte da população. Dessa forma, dispunha de meios pecuniários para a contratação de um mestre-escola, até porque, naquele tempo, além da influência de manter um mestre-escola na fazenda, havia uma redução nos gastos para manter os filhos em uma cidade mais distante. Era comum a prática envolver tanto a educação para os filhos do fazendeiro quanto para a comunidade local. O pagamento do esse profissional envolvia acomodação, alimentação, alojamento e dinheiro, de forma que custeasse suas roupas e necessidades básicas.

A aula era ministrada de segunda a sexta-feira, pela manhã, iniciando às $7 \mathrm{~h}$ e encerrando às $12 \mathrm{~h}$. Aos sábados, havia aula de catecismo para os alunos. As anotações eram feitas no quadro de giz, com tarefa para fazer em sala de aula. Eram propostos ditado de palavras, formação de frases, no caderno e no quadro de giz etc. Igualmente, existia o dia da tabuada, que era sexta-feira. O aluno escolhia, ou a professora perguntava a ele; quem errava, levava bolo de palmatória. Quando a professora questionava, quem acertava a resposta dava o bolo em quem errava - por isso, criava-se um clima de tensão e terror em função do peso da mão usado por alguns alunos ao usarem a palmatória, e do clima de vingança para a próxima aula de tabuada, por parte de quem levou um bolo muito forte.

Cada aluno possuía um caderno de caligrafia, um de português e um de matemática, um $\mathrm{ABC}$ e uma tabuada. A chamada era feita em um caderno de papel almaço, riscado de forma a permitir identificar a lista nominal, onde poderia marcar "P" ou "F" para os alunos presentes ou ausentes.

A escola não disponibilizava merenda, mas tinha recreio. As provas eram mensais e de dois tipos: oral e escrita. Os cadernos ficavam na escola, para que fossem corrigidas as tarefas na parte da tarde. Eram matriculados em torno de 50 alunos, de 7 a 14 anos. Funcionava em uma única sala de aula, com uma turma multisseriada. Houve situação de chegar a mais de 60 alunos, porque ocorria de autorizarem que alguns frequentassem e acompanhassem as aulas como ouvintes, porque já havia ultrapassado a idade estabelecida.

Uma vez por mês, a escola era visitada por fiscais. Eram três, que se revezavam nas visitas e chegavam sem avisar. Durante a inspeção presencial, eles acompanhavam a frequência dos alunos, em conformidade com os registros e as avaliações. Houve também algumas capacitações para a professora: Dona Pureza lembrou-se de pelo menos um treinamento realizado em Campo Maior e outro em Teresina, ocorridos em intervalos de três anos. Neles, eram reunidos professores de várias escolas rurais da região, durante dois 
dias, quando recebiam orientações de técnicos da Secretaria de Educação Estadual sobre a parte pedagógica e burocrática.

A professora Pureza ministrava aulas a alunos de diferentes idades, na mesma sala de aula, ligada à casa do fazendeiro Zé Estevam.

Lembro que uma vez, expulsei três alunos da sala porque faziam bilhete para as meninas e elas ficavam com raiva. Ensinava caligrafia, ditado, problemas e religião. A tabuada era discutida com palmatória, entre eles mesmos. Se um errasse, o companheiro queimava. Dois anos depois, o Sr. Zé Estevam foi falar com o prefeito da época, Ferdinand, para pedir uma professora pública para Palmeirinha. O Sr. Ferdinand falou para ele procurar uma professora, que iria nomeá-la. Ele disse: eu quero a que já está lá em casa. Assim, tornei-me professora pública (SOUSA, 2010).

As lembranças da entrevistada permitem fazer as seguintes análises, que são comuns por todo o Brasil do período analisado: os contratos de mestre-escola foram superados; estes passaram a ser professores públicos, contratados pela prefeitura; e, geralmente, as indicações para os cargos ocorriam pelo proprietário de terras. Outro fator é que o senhor Zé Estevam, para manter a escola na localidade, fez a doação de terras para a prefeitura construir o prédio público, anos depois.

Ao tornar-se professora pública em uma escola isolada, desempenhou todos os papéis possíveis: de diretora a zeladora e professora. $\mathrm{O}$ que mudou foi que a partir de então, o pagamento era mantido pelo poder público, implicando em algumas mudanças no espaço e tempo escolar, ou seja, ano letivo, férias, recreio, quantidade de alunos, documentos a preencher e quantidade de horário de aulas.

Anos depois, Dona Mariana, esposa do senhor Zé Estevam, adoeceu e foi buscar tratamento em Teresina (PI). Na época, foi necessária a realização de uma cirurgia. Diante da situação, a mesma pediu para que a Professora Pureza cuidasse de sua casa e de seus cinco filhos, o que prontamente foi aceito. Jesuíta Saraiva (filha de Mariana) relatou: "minha mãe estava doente e chamou todos os filhos, tomou benção, chamou Dona Pureza e pediu para que cuidasse dos seus filhos" (SOUSA, 2010). Dona Mariana não resistiu ao tratamento e veio a óbito. Assim, em 9 de maio de 1953, Dona Pureza casou-se com Zé Estevam e teve os seguintes filhos: Maria do Livramento (12.06.1954), João de Deus (08.03.1956), Teresa (08.08.1957), Antônia Saraiva (15.12.1958), Francisco Saraiva (20.04.1960), Irene Saraiva (13.01.1962) e José Saraiva de Sousa Filho (17.07.1964), e ainda criou Miguel, a partir dos 3 anos de idade.

Então, a professora Pureza teve vinte filhos (sete biológicos, 12 do casamento anterior de seu marido, e um adotivo ${ }^{5}$ ). Um deles era especial - teve paralisia cerebral ao nascer. Mesmo assim, ela conciliou a administração da casa, o cuidado dos filhos com a profissão de professora. Pode-se afirmar, portanto, que ela reuniu os papéis de rainha do lar e educadora da infância.

A esse respeito, Almeida (2000, p.82) aduz que

O exercício do magistério representava um prolongamento das funções maternas, e instruir e educar crianças era considerado não somente aceitável para as mulheres, como também a profissão ideal em vista de elas possuírem moral ilibada, sendo pacientes, bondosas e indulgentes para lidar com os alunos. 
O casamento com Zé Estevam favoreceu a permanência da professora na localidade, contribuindo, também para a sua atuação na mesma escola até a sua aposentadoria.

Todos os filhos foram para a Escola Municipal Estevam Joaquim de Sousa, sendo alfabetizados por ela, juntamente com os outros alunos da mesma idade. Os alunos aprendiam o $\mathrm{ABC}$ e a tabuada; passavam a conhecer o alfabeto; eram trabalhados, progressivamente, escrita e, oralmente, o conhecimento de palavras com uma, duas, três, quatro sílabas; realizava-se ditado de palavras; formação de frases, no caderno e no quadro de giz, etc. Este era utilizado para as anotações das tarefas e dos apontamentos. Em 1965, todos os filhos foram para José de Freitas estudar no grupo Padre Sampaio.

Comprei uma casa próxima aos correios. Estudaram primário e ginásio. Em 1975, comprei uma casa em Teresina, para os filhos estudarem o $2^{\circ}$ grau e o ensino superior. Vendi duas garrotas para comprar esta casa em Teresina. Contratei o pedreiro e o Senhor Rocha tomava conta. Dos Anjos morava com eles e todo sábado levava sacolas de mantimentos. Estudaram no Liceu (SOUSA,2010).

Observa-se que a instrução de Dona Pureza reverteu-se em favor da família, ao alfabetizar todos os filhos e incentivá-los à continuação dos estudos.

\section{APOSENTADORIA}

A professora foi aposentada após 25 anos no serviço público, em 1980. Dona Pureza foi nomeada por volta de 1952/53. Não foi encontrado registro escrito da nomeação, mas tirou-se a conclusão com base na conversa com ela e com alguns filhos mais velhos do Sr. José Estevam e no ano da aposentadoria, ocorrido entre 1977/1978, depois de completar 25 anos de serviço efetivo em sala de aula. José Estevam faleceu em 06 de abril de 1984.

Conceição Batista - Minha primeira professora. Hoje também sou professora e percebo o valor do primeiro professor. Era escola isolada. Lembro-me da tabuada. Não me lembro dela bater. Eram os próprios alunos que colocavam o papel com as letras para dizermos qual era e, se não acertasse, levava bolo do colega.

Raimundo Triunfo (aluno) - Me crivou as primeiras letras. Era uma pessoa humana, nos ensinou ter respeito pelos outros. Nós íamos receber o inspetor, na hora que a pessoa chegava, levantávamos para ficar de pé para saudar. Fazia a chamada, ensinava, cantava o hino nacional. Foi uma pessoa especial, segunda mãe, magnífica e especial.

Livramento - Exemplo de educação e de mãe. É o elo na família.

João de Deus - Foi nossa professora cuidou dos filhos. Parte do nosso sucesso deve-se a ela (SOUSA, 2010).

Pelos depoimentos acima, analisa-se a construção da tessitura mulher-mãeprofessora que Dona Pureza representou. Como diz Almeida (2000, p. 62), "aquela que ilumina a senda do saber e da moralidade, qual mãe amorosa debruçada sobre as frágeis crianças a serem orientadas e transformadas por dedos que possuem a capacidade natural de desenhar destinos e acalentar esperanças". 
Sobre a escolha da profissão, Dona Pureza relatou que "era o melhor ramo de trabalho que tinha". Isso encontra embasamento teórico em Almeida (2000), quando afirma que durante as primeiras décadas do século $\mathrm{XX}$, no Brasil, o magistério era praticamente a única carreira aberta para as mulheres, apesar de algumas procurarem pela enfermagem. "O fato de não terem amplo acesso às demais profissões fez do magistério a profissão mais adequada para o sexo feminino, o que foi reforçado pelos atributos de missão e vocação, além da continuidade do trabalho do lar" (ALMEIDA, 2000, p. 77).

\section{CONSIDERAÇÕES FINAIS}

O trabalho realizado por meio da pesquisa possibilitou as seguintes conclusões: é possível compreender o processo histórico educacional por intermédio da história de vida de um professor; notar a presença do mestre-escola no interior do Piauí, ainda na década de 60, do século XX, já que no Brasil, isso foi mais comum durante o Império; mestres-escola também foram nomeados professores públicos; o sistema casa-escola ainda predominou no Piauí anos após a criação dos grupos escolares; o modelo de escola em que a professora Pureza trabalhou teve características similares às da época do Império, ou seja, o fazendeiro local contratava a professora, que educava toda a comunidade da região, fornecendo a ele um pagamento, casa e comida; ademais, a prática de Dona Pureza influenciou a inauguração de uma escola na comunidade Palmeirinha, mantida pelo poder público até hoje; por último, como professora, ela conseguiu conciliar seu trabalho às funções de mãe, esposa e diretora de escola.

\section{Referências}

ALMEIDA, Jane Soares. Mulheres na educação: missão, vocação e destino? A feminização do magistério ao longo do século XX. In: SAVIANI, Demerval. et.al. O legado educacional do século XX no Brasil. Campinas (SP): Autores Associados, 2004.

COSTA FILHO, Alcebíades. A escola do sertão: ensino e sociedade no Piauí, 1850-1889. Teresina: Fundação Cultural Monsenhor Chaves, 2006.

FERRO, Maria do Amparo Borges. Educação e sociedade no Piauí republicano. Teresina: Edufpi, 1996.

GOODSON, Ivo F. Dar voz ao professor: as histórias de vida dos professores e o seu desenvolvimento profissional. In: NÓVOA, Antonio. (Org.). Vidas de professores. Portugal: Porto editora, 1995.

VILLELA, Heloísa de O.S. O Mestre-escola e a professora. In:LOPES, Eliane Marta Teixeira; FARIA FILHO, Luciano Mendes; VEIGA, Cynthia Greive. 500 anos de educação no Brasil. 3. ed.1. reimp. Belo Horizonte: Autêntica, 2007.

REIS, Amada de Cássia Campos Reis. História e memória da educação em Oeiras (PI): de meados do século XVIII à primeira metade do século XX. Teresina (PI): Expansão/ EDUFPI, 2009.

SOUSA, Jane Bezerra de. Ser e fazer-se professora no Piauí no século XX: a história de vida de Nevinha Santos. Uberlândia, UFU, 2009.221f.Tese defendida no Programa de Pós Graduação da Universidade Federal de Uberlândia, 2009.

SOUSA, Marcondyys. Dona Pureza: 90 anos. Son.,Color.,José de Freitas, 2010. 
TITO FILHO, A. Disponível em: <http://acervoatitofilho1.blogspot.com.br/2010/10/outros-padres.html. Jornal o Dia 17/06/1988>. Acesso em: 24 out. 2013.

VEIGA, Cynthia Greive. História da educação. São Paulo: Ática, 2007.

Notas

\footnotetext{
${ }^{1}$ Protocolo CAEE 31174414.0.0000.5214
}

${ }^{2}$ Professora da Universidade Federal do Piauí. CCE/DEFE. Doutora e Mestre em educação. Licenciada em pedagogia e História. E-mail: jane_bezerrasousa@yahoo.com.br

${ }^{3}$ Profissão: Fazendeiro/agricultor/pequeno proprietário. José Saraiva de Sousa, mais conhecido como José Estevam (denominação vinda do pai, Estevam), era fazendeiro, comerciante e líder político local. Subdelegado e liderança política na região, intermediava a solução dos problemas locais, todos da comunidade o procurava solucionar outras questões, como: tirar documento, providenciar transporte de doentes para a cidade, prender e encaminhar para a cidade pessoas envolvidas em furto, entre outros. Por volta de 1970, fechou o comércio e dedicou-se mais à agricultura, à pecuária e ao extrativismo, nos moldes de atividade de subsistência. Nasceu em 17 de dezembro de 1904, na localidade Palmeirinha. Filho mais velho de Estevam Joaquim de Sousa e Umbelina Saraiva de Moura, casou-se com Mariana Saraiva de Sousa em agosto de 1929, com quem teve 12 filhos, sendo seis mulheres e seis homens. Ficou viúvo em outubro de 1952 e casou-se novamente em abril de 1953, com Dona Pureza, a professora particular dos filhos. Com ela teve sete filhos, sendo quatro homens e três mulheres, totalizando 19 filhos dos dois

${ }^{4} \mathrm{O}$ primeiro nome era Escola Isolada Barão do Rio Branco. Com a construção do novo prédio, pela prefeitura, em terreno doado por José Estevam, em 1970, a escola foi denominada Escola Municipal Artur da Costa e Silva. Em 2002, na gestão do prefeito Pedro Paulo, a escola mudou de nome novamente, sendo denominada Escola Municipal Estevam Joaquim de Sousa, em homenagem ao fazendeiro pai de José Saraiva, já falecido e fundador da comunidade. A Escola Municipal Estevam Joaquim de Sousa hoje possui quatro salas de aula e uma diretoria. Funciona pela manhã, com ensino fundamental menor, e à tarde, com ensino fundamental maior. Segundo o ex-diretor da Escola, Valdemar Saraiva, a instituição chegou a ter em torno de 150 alunos matriculados há alguns anos. Atualmente, a matrícula vem reduzindo, girando em torno de 100 alunos, de $1^{\circ}$ ao $9^{\circ}$ ano, situação possivelmente influenciada pela queda da natalidade e do êxodo rural.

${ }^{5}$ Miguel ficou órfão com três anos, dessa forma foi adotado por Zé Estevam e Dona Pureza.

Recebido: $\quad$ junho-15 Aprovado: fevereiro-16 